\title{
Success factors in Balanced Scorecard implementations - A literature review ${ }^{* *}$
}

This paper uses Buchanan et al.'s (2005) framework of change to systematically synthesize the empirical literature on the implementation processes of the Balanced Scorecard (BSC). We specifically examine which critical success factors (CSFs) have been neglected so far, but may play a substantial role in improving BSC implementations. While some CSFs are intuitive (such as top management support), others seem to be overrated by the conceptual literature (e.g., the speed of the implementation). Most importantly, the BSC literature has some blind spots that relate to cost-benefit analyses of the BSC, the impacts of management skills and leadership, power and politics, organizational culture, and public discourse.

Key words: Balanced Scorecard, success factors, performance measurement system, implementation process, organizational change, literature review (JEL: M10, M40, M48, M52)

* Rainer Lueg (corresponding author) Associate Professor of Management Accounting and Control, Aarhus University, School of Business and Social Sciences, Department of Economics and Business, Fuglesangs Allé 4, 8210 Aarhus V - Denmark.

E-mail: rlueg@asb.dk.

Louisa Vu, Research Assistant, Aarhus University, School of Business and Social Sciences, Department of Economics and Business, Fuglesangs Allé 4, 8210 Aarhus V - Denmark.E-mail: louisathuy@hotmail.com.

** Acknowledgement: This paper is part of a larger research project on the Balanced Scorecard (Albertsen \& Lueg, 2014; Lueg, 2015; Lueg \& Carvalho e Silva, 2013; Lueg \& Julner, 2014), and we appreciate the contribution of Oana Alexandra Albertsen to this work. We are also thankful for the helpful comments by the editor and the anonymous reviewers.

Article received: October 9, 2014

Revised version accepted after double blind review: May 21, 2015. 


\section{Introduction}

Over the past 20 years, Kaplan and Norton's (1992) Balanced Scorecard (BSC) has attracted considerable interest from academia and practice (for a general review of the BSC-literature, cf. Hoque, 2014). With the increase in popularity, the BSC has evolved from a simple performance measurement system to a strategic management system (Kaplan \& Norton, 2001a). Kaplan and Norton (1996) make the normative claims that the BSC enables organizations to clarify and translate vision and strategy into measureable outputs; communicate and link strategic objectives and measures; plan, set targets, and align strategic initiatives; and enhance strategic feedback and learning. Lawson, Desroches and Hatch (2008) argue that $62 \%$ of large organizations worldwide use BSC-style practices. In the U.S., BSC adoption rates are reported to be between 40-50\% (Marr, 2001; Williams, 2001), and 57\% in the U.K. (Anonymous, 2001). Among the largest listed organizations in the German-speaking area, 24\% claim to have adopted the BSC (Speckbacher, Bischof, \& Pfeiffer, 2003). Yet, the researchers Speckbacher, Bischof and Pfeiffer (2003) are more critical and only agree with 7\% of the respondents that they have really implemented a full BSC. According to a recent international survey from Bain \& Company among 1,208 executives across countries and organizational types, the BSC is the fifth most frequently used management practice among contemporary organization: approximately $20 \%$ of the respondents use the BSC, and their average satisfaction level ranges around '4' on a 5-point Likert scale (Rigby, 2013). The BSC shares this top-5 position with inevitable practices such as customer relationship management and benchmarking, and its popularity even surpasses crucial practices of a business such as supply chain management or outsourcing.

However, it is intriguing to notice that many organizations still have not adopted the BSC despite the ostensible benefits consulting firms like to promote. One conjecture from the contingency literature could be that these organizations see the BSC as not performance-optimal in their specific contexts and therefore do not want to use it in the first place (Chenhall, 2003). An alternative conjecture from the organizational change literature could be that many non-adopters would actually like to use the BSC, but they expect or have experienced that they do not have the necessary capabilities to implement it (Buchanan, Fitzgerald, Ketley, Gollop, Jones, Lamont, \& Whitby, 2005). In this paper, we would like to understand this second conjecture better. This requires a closer look at the existing literature on the initial processes of implementations (Buchanan et al., 2005) rather than the quite different literature that assesses the fit between an already implemented BSC and the organization (Chenhall, 2003). According to Chan (2004), managers only concur that the benefits of the BSC outweigh its costs if it is implemented thoroughly. However, this implementation process is expensive, time-consuming, and subject to uncertainty. Some of the key reasons why organizations choose not to implement the BSC are inadequate information systems, organizational resistance to change, and insufficient sponsorship of the BSC by senior managers (Northcott \& Taulapapa, 2012). A prerequisite for a BSC implementation is to know the critical success factors (CSFs), such as the resources needed, or the key ac- 
tors to involve. Thus, we pose the question: Which are the critical success factors for a successful implementation of the BSC?

In order to reach this level of understanding, we conduct a systematic literature review (Denyer \& Tranfield, 2009). We specifically analyze which success factors from the general literature on organizational change have been ignored by researchers, or are seen as irrelevant in practice.

We organize our findings along the established framework on organizational change by Buchanan et al. (2005) to see how BSC implementations measure up against general organizational change. Hardly surprising, BSC implementations crucially depend on the substance of the BSC (e.g., cause-and-effect chains), individual inclinations (e.g., lower level employee resistance), and organizational factors (e.g., resources). It is more noteworthy that success factors listed by Kaplan seem to be of lower importance, i.e., the time frame for the implementation and processual factors. Most importantly, we identify blind spots in the literature: these relate to hard facts, such as the absence of ex-ante cost-benefit analyses on the BSC, and they relate to abstract facts, such as questioning the skills and motivations of the concerned middle and top managers, and the roles of organizational culture, power structures, and public discourse/social norms that have shown to affect the implementation of management practices similar to the BSC.

The remainder of the paper is structured as follows: section 2 presents the theory underlying the BSC, its implementation process, and our framework of analysis. Section 3 explains our methodology. Section 4 elaborates on the most relevant factors that play a role in organizations' implementation processes. Section 5 discusses the theoretical and practical implications and recommends areas for future research.

\section{Theoretical background}

\subsection{The Balanced Scorecard, its critics, and other management practices}

The BSC enables an organization to link its short-term performance targets with its long-term strategic goals through a combination of financial and nonfinancial measures (Kaplan \& Norton, 2001a). This implementation of a BSC facilitates comprehensive strategic alignment throughout an organization (Kaplan \& Norton, 2006, 2008a). This alignment is ensured through a chain of cause-and-effect relationships that link lagging and leading indicators (Kaplan \& Norton, 2001b, 2001c). The standard BSC is divided into four perspectives: financial, customer, internal processes, and learning and growth. These must be adjusted as required by the organizational context (Kaplan \& Norton, 1996, p. 34). The idea is for an organization to reach its desired long-term economic performance goal through sequential actions, starting with the employees and systems, then the internal processes, and finally the customers that lead to financial success. By identifying objectives, and selecting measures and targets in the respective perspectives, the BSC mirrors the strategy of the organization through cause-and-effect relationships (Kaplan \& Norton, 2004a, 2004b, 2008b).

Besides the praise, the BSC has also received much criticism over the years. This includes its a-theoretical approach, its detachment from accounting numbers and an unambiguous bottom line, its unintended breaches of the controllability principle at 
the level of middle managers, its deterministic view of management with generic actions, the ostensible statistical validity of its cause-and-effect relationships, and the nonacademic mystical speech-genre of Kaplan and Norton's books in which the top manager functions as the hero that enforces strategy on disoriented subordinates Jakobsen \& Lueg, 2012, 2014; Lueg \& Nørreklit, 2012; Nørreklit, 2000, 2003; Nørreklit, Jakobsen, \& Mitchell, 2008; Nørreklit, Nørreklit, Mitchell, \& Bjørnenak, 2012; Zimmerman, 2001). These criticisms indicate that the application of the BSC might not be as easy as Kaplan and Norton postulate, thereby giving us another good reason to survey the literature for evidence from the field.

The BSC differs from other management practices in several aspects. First, the BSC belongs to the strategic management practices, which distinguishes it from many operative ones. Second, it is a comprehensive practice that should be implemented across an entire organization and does not tolerate other control systems besides it. Third, the BSC uses both financial and non-financial information and thereby has a much broader focus than costing practices. Fourth, the BSC uses both lagging and leading indicators that allow feed-forward-controls. Therefore, the success factors in the much broader implementation processes of a BSC differ from narrower management practices. These differences justify a specific review on the implementation process of the BSC.

\subsection{Implementation process}

Implementation processes of management practices like the BSC appear in the literature under different terms, such as adoption (Ansari, Fiss, \& Zajac, 2010), integration (Barki \& Pinsonneault, 2005; Ittner \& Larcker, 2001), or organizational/accounting change (Andon, Baxter, \& Chua, 2007; Van de Ven \& Poole, 2005). They depict the initiation of a new practice in an organization. The model of Barki and Pinsonneault (2005) highlights that the success of the implementation process depends on success factors and barriers. Furthermore, the model makes a clear distinction between the impact of the new practice on organizational performance. Its performance depends on organizational configurations and environmental turbulence, and it only fully reveals itself as the management practice matures, e.g., when it is adapted (Ansari et al., 2010; Chenhall, 2003) or used for different purposes (Simons, 2005). Our literature review focuses on the former part of the model, i.e., the CSFs of implementing a BSC.

The literature on the BSC does not suggest one best way of implementation. It does, however, offer guidance. Kaplan and Norton (2008a) formulate six steps: 1) develop the strategy, 2) plan the strategy, 3) align the organization, 4) plan operations, 5) monitor and learn, 6) test and adapt. Papalexandris, Ioannou and Prastacos (2004) also suggest that an organization goes through six phases in its implementation of the BSC. Quite similar, Niven (2011) recommends a two-phase procedure consisting of 16 steps altogether. What differentiates the suggestions is the extent to which the authors have chosen to elaborate on the phases by subdividing them into additional steps. However, we find that the content of these alternative steps is essentially consistent with Kaplan and Norton (2008a).

Kaplan lists only four pitfalls (implicitly by naming success factors) of implementing a BSC: lack of top management support, lack of employee involvement, too long 
lead times until the BSC is initially used, and misunderstanding the main goal of the BSC, i.e., that the BSC has to become the ultimate yardstick for managing an organization (Atkinson, Kaplan, Matsumura, \& Young, 2011, p. 71-72). This rather short list contrasts with the comprehensive literature review of Buchanan et al. (2005): the authors survey the literature on organizational change to identify 11 partly overlapping $\mathrm{CSF}$ that may lead to the sustainable implementation of a management practice. Buchanan et al. (2005, p. 189) highlight that the importance of each of these CSFs is not universal but depends on the investigated management practice (cf. Figure 1).

Figure 1: Framework of success factors for BSC implementation based on Buchanan et al. (2005)

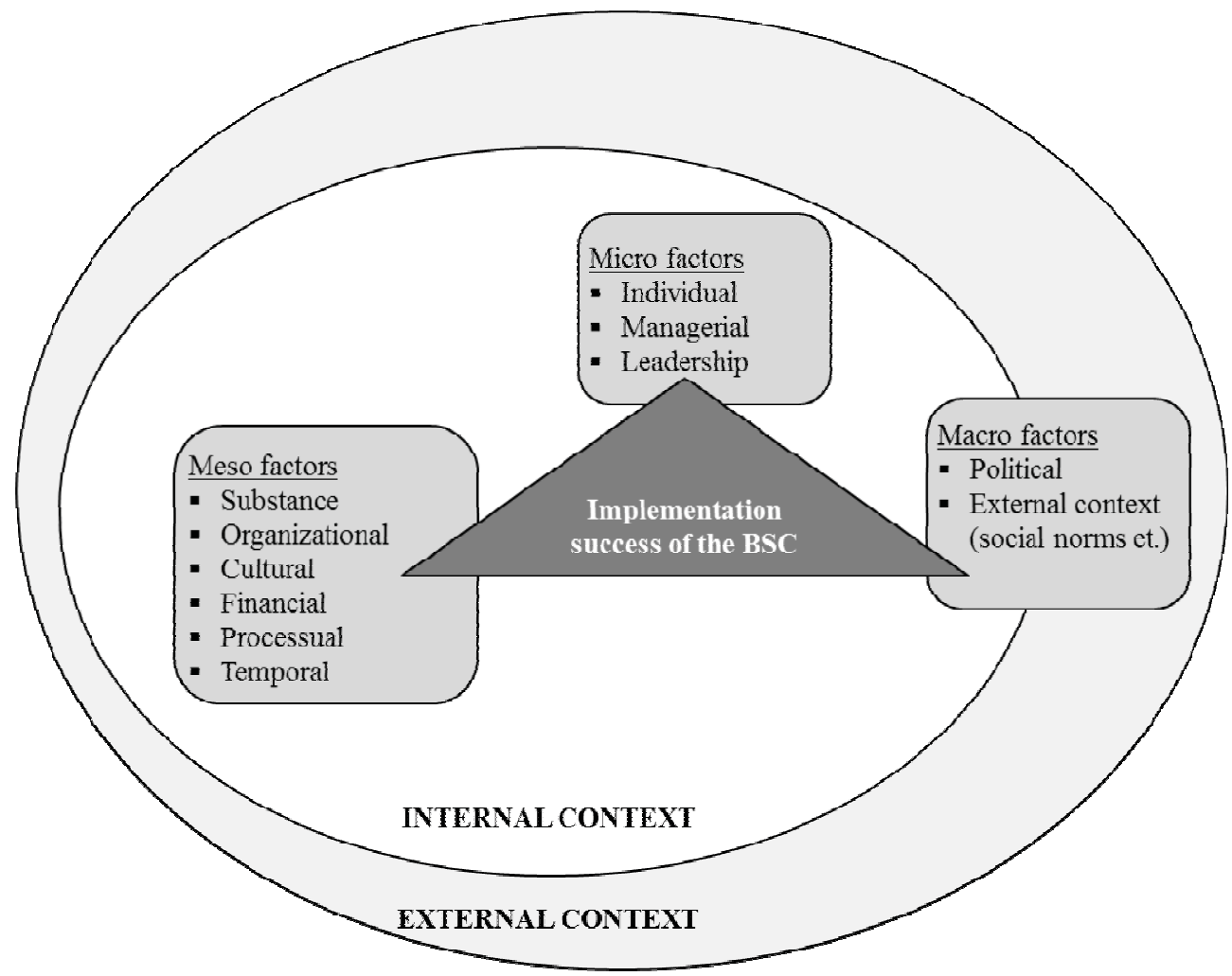

We use their framework to structure our literature review, because it allows us to investigate success factors of BSC implementations at the macro level (e.g., external context), the meso level (e.g., organizational factors), as well as at the micro level (e.g., individual factors). It will also enable us to substantiate a discussion if some factors have little importance for the BSC, or if they have simply not been researched yet. Based on Buchanan et al. (2005), we elaborate on the 11 factors in the following and suggest specific examples for BSC implementations:

Substance describes if the BSC becomes the basis of managerial actions, e.g., through alignment with the strategy or as an uncontested planning and control system for organizational performance. 
Individual factors address the involvement of actors in the implementation process. They include openness of actors toward change and innovation with the BSC as well as their capabilities to enact this change. They also address fear, uncertainty and resistance at the individual level, and the degree to which actors are able to deal with these emotions.

Managerial factors list promising competencies of implementing managers. They include if managers are willing to accept and address problems of the BSC implementation, looking for their root causes, and finding log-term solutions. They also comprise the abilities of management to find solutions outside the box, delegate, create legitimacy, trust and credibility, e.g., by being an example in adjusting their own behavior according to the BSC.

Leadership factors mainly summarize how much top management supports the BSC morally or with resources and how credible this support is perceived to be by the involved actors. These include clear visions for the BSC implementation, challenging but realistic goals, and durable priorities.

Organizational factors comprise all types of structures and policies, which makes this category quite open to interpretation (Buchanan et al., 2005). They entail the empowerment and the facilitation of team work in flexible and responsive structures, sufficient training and budgetary resources, effective communication channels, transparent recognition and incentives that point toward a sustained implementation, and policies that ensure that problems are addressed and the key aspects of the business model are upheld during implementation (e.g., customer satisfaction and quality).

Cultural factors address if new behaviors are commonly rooted in beliefs, norms, and values of the actors across the organization. For instance, actors should feel the need to go beyond the BSC's static measures, gauge if the BSC makes the organization aim for the right goals, and assess the needs for a range of stakeholders.

Political factors aim at understanding the interests and power of diverse coalitions to enforce or stop the implementation, e.g., management, the supervisory board, or unions that oppose the BSC's transparency.

Financial aspects mainly question if - from an ex-ante perspective - the benefits of the implementation will most likely outweigh its total cost. As to the BSC, this could be a cost-benefit analysis before resources are spend on the implementation.

Processual factors check if steering committees are set up that uphold the management practice after its initial implementation, such as regular strategy meetings to update the BSC.

Contextual factors depict if the implementation is in line with wider social norms. For example, the BSC could be so popular in some contexts that its implementation becomes somehow mandatory, while in other contexts, shareholder activists would fight the BSC.

Temporal factors describe if the implementation had the correct flow of events and an appropriate time frame. Contrary to many other management practices, Kaplan and Norton (1996, p. 309) recommend implementing the BSC within a maximum of 16 weeks to preserve momentum. 


\section{Methodology}

\subsection{Literature search procedure}

We choose the established methodology of a systematic literature review (Denyer \& Tranfield, 2009; Lueg \& Schäffer, 2010; Rousseau, Manning, \& Denyer, 2008; Tranfield, Denyer, \& Smart, 2003), which is "a review of the evidence on a clearly formulated question that uses systematic and explicit methods to identify, select and critically appraise relevant primary research, and to extract and analyse data from the studies that are included in the review" (Khan, ter Riet, Glanville, Sowden, \& Kleijnen, 2001, p. 4). Our literature search comprised four steps.

First, we selected the databases EBSCO, ScienceDirect, and ABI Inform to ensure a broad coverage of the literature beyond a limited selection of journals. We searched for the exact expression 'Balanced Scorecard' covering the time frame from the BSC's inauguration in 1992 to 2012. This yielded 1,031 articles.

In a second step, we kept only the empirical articles in order to get a realistic picture of relevant success factors beyond purely theoretical considerations. This reduced our dataset from 1,031 articles to 315 articles.

In a third step, we ensured a minimum academic quality of these articles and only further considered journals that were ranked at least with 2 out of 4 stars on the ranking of the Association of Business Schools (Harvey, Kelly, Morris, \& Rowlinson, 2010). We also checked the references of these remaining articles in order to identify other possibly relevant studies on BSC implementations that had been published in other sources like books or conference proceedings (ancestor approach). We did this because such sources appear to be of value to the authors of the high-quality articles. This reduced the set of 315 articles to 117 articles.

Fourth, we read the titles, abstracts, and keywords of these papers. Specifically, we looked for the Boolean terms 'implement*; 'integrat*'; 'adopt*'; 'introduc*'; 'switch*'; and 'change*'. We only took into account articles that explicitly consider the process of implementation and organizational change as their main topic, not the use of already implemented BSCs. This led to a final sample of 26 articles on BSC implementations.

\subsection{Limitations of our approach}

Our approach has some limitations that might have led us to overlook or misinterpret some relevant information (Denyer \& Tranfield, 2009). First, it is possible that some relevant articles have been left out of the databases we searched. Second, we focus specifically on the BSC, thereby possibly omitting relevant or similar, balanced management practices. Third, our selection of peer-reviewed research from journals does not include books, conference presentations, or working papers. Also, it might ignore groundbreaking investigations that are too unconventional for traditional research outlets. Fourth, the reviewed studies are grounded in different ontologies and etymologies, which limit the comparability of their findings. We accommodate these limitations by forming cautious interpretations and conclusions that avoid strong claims. 


\section{Analysis of the empirical literature}

In the following, we categorize the findings of the identified articles according to our framework and discuss their commonalities.

\subsection{Substance}

An apparent recipe for successful BSC implementation is the design of the BSC. Organizations specifically struggle with the measures and the cause-and-effect relationships. Kasurinen (2002) describes an implementation that was not completed because actors at different units of the company could not clearly derive from the strategy which products needed to be prioritized. Some organizations start selecting the measures by reviewing existing performance metrics with respect to their linkage to strategy (similar: Andon et al., 2007; Butler, Letza, \& Neale, 1997; Fernandes, Raja, \& Whalley, 2006; Garengo \& Biazzo, 2012; Grando \& Belvedere, 2008; Papalexandris et al., 2004). This bottom-up approach indicates that the organizations use performance information as the starting point. Incorporating existing measures in the BSC capitalizes on the effort already allotted in measuring performance (Papalexandris et al., 2004). It allows employees to benefit from already collected data (Grando \& Belvedere, 2008) and work with familiar and commonly understood metrics (Papalexandris et al., 2004). However, it also indicates that organizations use existing measures instead of new ones.

Decoene and Bruggeman (2006) illustrate the opposite case where top management cascades measures as suggested by Kaplan and Norton (2006). The authors find that employees and middle managers perceive these measures as uncontrollable, which lowers their motivation. Kasurinen (2002) and McAdam and Walker (2003) present the continuous existence of the old performance measurement system prevents a full implementation of the BSC. Modell (2009) identifies the same problem and provides evidence that the newly implemented BSC was overly theoretical and alienated employees from their daily operations. As a consequence, the BSC was never accepted as a new management practice. Problems with the new measures include nonquantifiable measures (Kaplan \& Norton, 1993) and limiting the number of measures (Butler et al., 1997). In non-profit organizations such as health care, measurement with reliability and precision proves to be particularly difficult and needs to be specifically adjusted to the needs of that industry (Aidemark, 2002; McAdam \& Walker, 2003; Modell, 2009).

However, the bigger obstacle is establishing causal linkages between the strategic objectives in the BSC. Since a main factor that contributes to the effectiveness of the BSC as a performance management system is the suitability of the performance indicators, a significant effort is devoted to selecting the performance indicators with strong correlations (Papalexandris et al., 2004). Ahn (2001) specifically alerts that only the most important links should be on the BSC's Strategy Map to prevent a confusing network of causal relations. Most empirical literature agrees that linking the strategic objectives is a process based on 'speculative' correlation between each BSC perspective and the strategic objectives (Ahn, 2001; Papalexandris et al., 2004). The subjectivity associated with the linkages of the strategy map leads to time-consuming arguments 
about the actual correlation of the chosen objectives. Papalexandris et al. (2004) and Kasurinen (2002) report that logic or statistical relations do not always prevail across organizational units. The authors show that subjectivity and personal values made it necessary for organizational actors to cast a vote in order to resolve their conflicts. The conceptual recommendation that cause-and-effect relations should be expressed in "if-then" statements (Kaplan \& Norton, 1996) is insufficient, as it is always possible to find arguments in favor of links (Ahn, 2001). Similar, the findings of Jazayeri and Scapens (2008) contradict the prescriptions of Kaplan and Norton (2001a). They suggest that consistency in performance measurement is more important for employees than causal relationships.

Specifically in non-profit organizations, the idea of cause-and-effect chains either receives limited attention or is deliberately omitted. There are doubts about the feasibility of finding valid and stable causal relationships (Kasperskaya, 2008; Modell, 2009). This could be due to the fact that the foundations of the BSC are different in each organization. The perspectives are viewed as circular relationships or as a network in balance instead of a hierarchy with unidirectional relationships (Aidemark, 2002; Andon et al., 2007; Garengo \& Biazzo, 2012).

\subsection{Individual factors}

Employees can resist change due to a limited willingness to change (Jazayeri \& Scapens, 2008). This lack of motivation can be the result of not involving middle managers in the development of the BSC (Kasurinen, 2002; McAdam \& Walker, 2003; Modell, 2009). Low motivation also occurs when employees are reluctant to accept new measures alongside the numerous measures already present in the reporting system (Ahn, 2001; Andon et al., 2007). Also, employees can be skeptical about the benefits associated with the BSC when they believe that the benefits accrue slowly, but costs accrue quickly (Butler et al., 1997; Papalexandris et al., 2004). Others are less than enthusiastic about the additional freedom and empowerment they are given. They are not fond of the heightened visibility and transparency the BSC brings. A main reason is that the BSC annuls the experience that employees have gained making internal trade-offs or gaming the existing accounting system (Kaplan \& Norton, 1993).

Resistance can also be due to limited abilities to change, despite high motivation. Butler et al. (1997) find that - even if personal attitudes towards the idea of the BSC are positive - they are not always translated into actions. It is necessary for the actors to understand how the chosen strategy cascades through an organization. Evans (2005) adds that employees need to be made aware of the strategic intent and the impact of operational activities upon BSC implementation to avert dysfunctional behavior. In the case of Kasperskaya (2008), the BSC is only understood by the few senior managers who administer the project. Even though middle managers agree on the virtues of the BSC, they only provide superficial, formal support. At the same time, they passively resist by sticking to familiar routines. This resistance stems from a combination of technical problems and a missing link from the BSC to concrete job responsibilities. This eventually leads the organization to the decision of detaching its operational activities from the BSC (Kasperskaya, 2008). 
Contrary to resistance to change, involvement increases the support of individuals. Several authors highlight the importance of involving the employees in developing the BSC (Ahn, 2001; Butler et al., 1997; H. H. Chang, 2009; Elefalk, 2001; Fernandes et al., 2006; Kaplan \& Norton, 1993; Papalexandris et al., 2004). Actors can develop the specific objectives of their units and choose the measures to be placed on the BSC (Ahn, 2001; Butler et al., 1997; Grando \& Belvedere, 2008; Papalexandris et al., 2004). This ensures that their opinions will be taken into account and that consensus can be reached (Ahn, 2001; Chang, 2009; Kaplan \& Norton, 1993; Papalexandris et al., 2004). Jazayeri and Scapens (2008) document a specifically interesting case with which they suggest that a BSC-like system is successfully implemented if its design emerges bottom-up from employees. At the same time, the strict top-down cascading and alignment of top management plans as suggested by Kaplan and Norton (2006, 2008a) appears to be a hindrance (Jazayeri \& Scapens, 2008). In particular, the early involvement of employees in the BSC development reduces resistance to change and contributes to achieving ownership of the BSC project, which in turn has a positive effect on employee motivation (Papalexandris et al., 2004). Fernandes et al. (2006) document that even a simple questionnaire is effective in capturing the employee's reaction and commitment to the project. Kaplan and Norton (1993) state that the process of full involvement can take very long. They report how a division manager at a manufacturing organization described his own three-stage implementation process after receiving a directive to implement a BSC: denial ("bope it goes away"); medicinal ("it will not go away, so let us do it quickly and get it over with"); ownership ("let us do it for ourselves"). Kaplan and Norton - as the inventors of the BSC - could be seen as biased and overenthusiastic empirical authors.

Yet, Andon et al. (2007) also provide a negative example of involvement where employees co-developed and manipulated their performance measures in a way that it served their own interest, had dysfunctional effects on the business model, and led to the rejection of the BSC.

Furthermore, employees' perceived performance will be significantly better if goals are set unilaterally by the management. Organizations should actively encourage the employees to suggest means by which the vision and strategy can be achieved (Elefalk, 2001). This engages the employees in the future of the organization and encourages them to be part of the implementation. Commitment is created when the employees can see how their particular actions contribute to the achievement of the objectives of the organization.

\subsection{Managerial factors}

The literature suggests that the sustainability of the BSC is higher if implementing managers are competent enough to be critical toward the BSC and challenge its validity during implementation. Papalexandris et al. (2004) suggest how an organization assesses its managers' skills through a structured questionnaire. McAdam and Walker (2003) extract from their four comparative case studies that managers need to be open to admitting and addressing problems during the implementation. They document how some managers oversimplified the process and ignored the inaccurate and inadequate information on which the BSC was built. This led to a loss of credibility of these 
managers and prevented a full implementation. Kasurinen (2002, p. 332) suggests that the shortcomings of less capable and less critical middle managers can be compensated for. He shows that top managers' support can be sufficient to enforce the implementation of the BSC. This suggests a complementary effect of middle and top managers on BSC implementations.

\subsection{Leadership factors}

The empirical literature indicates that effective implementation requires top management participation and support (Kasperskaya, 2008; Kasurinen, 2002; Lohman, Fortuin, \& Wouters, 2004; Papalexandris et al., 2004; Perera, Schoch, \& Sabaratnam, 2007; Phadtare, 2010). Fernandes et al. (2006) argue that this is due to the fact that only top management has the authority to grant resources. Moreover, experienced managers possess more skills to keep the implementation process going smoothly and efficiently (Fernandes et al., 2006). Also Kaplan and Norton (2008a) underline that no organization reporting success with the BSC as a management system had an unengaged or passive leader. McAdam and Walker (2003) suggest from their four case studies that BSC implementations are substantially facilitated if leadership establishes clear goals for the implementation. In sum, the literature suggests that top management support is an antecedent of resources. Thereby, it is a necessary condition for the BSC to succeed, but not a sufficient one.

\subsection{Organizational factors}

Buchanan et al. (2005) leave room for interpretation on what a comprehensive list of organizational factors is. We will discuss what we can extract from their article, namely resources, training, rewards, and resolution of conflicts.

Resources: Organizations are aware that BSC implementations are complex and lengthy processes which require substantial commitment of tangible (e.g., budgets) and intangible (e.g., time) resources (Andon et al., 2007; Evans, 2005). Many nonadopters give the anticipated need for resources as a reason not to adopt the BSC (Perera et al., 2007). This indicates that organizations refrain from adopting the BSC, not only because it might be a misfit (Chenhall, 2003), but because they seem themselves incapable of completing the implementation process. Often, even more resources than expected are required in regard to the introduction and understanding of the BSC concept itself. Ahn (2001) suggests that organizations deem the very generally expressed conceptual recommendations for developing the BSC insufficient. This can cause significant problems, since a detailed elaboration of the BSC consumes large amount of resources (McAdam \& Walker, 2003). Fernandes et al. (2006) describe that some organizations attempt to circumvent the bottleneck of scarce human resources by employing external labor. Yet, the authors show that organizations face problems in identifying which consultants have the skill to effectively assist in the hands-on implementation of the BSC (similar: Andon et al., 2007). To be able to deliver the most reliable data, data specialists, IT staff, and other employees should be allowed to spend much time on such a process. If they are rushed, the required data might not be ready. This can result in an implementation stall (Fernandes et al., 2006; Lohman et al., 2004; Papalexandris et al., 2004). Both non-profit and for-profit organizations face problems with collecting and processing such information (Ahn, 2001; Kasperskaya, 
2008). Means such as Microsoft Excel, Visual Basic, ERP systems, or one of the plentiful BSC-specific software solutions allow the BSC to be initiated more swiftly. Papalexandris et al. (2004) quote some hard numbers on the unexpected resource needs. They document that even an almost problem-free, by-the-book BSC implementation easily overruns the budget by $30 \%$.

Rewards: Reward systems play a pivotal role in reducing resistance and ensuring commitment from staff (Chang, 2009; Decoene \& Bruggeman, 2006; Farneti, 2009). They motivate strategy execution through the link of accountability and rewards (Chang, 2009). However, reward systems that focus on a limited set of measures might lead to dysfunctional behavior. This includes sub-optimization of some areas of business while other areas of importance may be neglected. Modell (2009) suggests that such dysfunctional behavior is not even rooted in bad intentions: omitting the link between the BSC and performance assessment simply leaves employees in the dark about which measures matter the most.

Training: Some authors mention that training is an essential factor for successful implementation of a BSC (Ahn, 2001; Akkermans \& Van Oorschot, 2004; Chan, 2004). Chang, Tung, Huang, \& Yang (2008) report on training in the form of workshops and open presentations. Workshops helped explain the purpose of the BSC and determine the approach to implementation. The presentations allowed the respective units to present their results, get feedback, and learn from one another. Training seems to have a visible effect: McAdam and Walker (2003) compare the BSC implementations in several companies. Compared to their control group without training, the effect of BSC-specific training of employees is a major facilitator of successful implementations.

Cross-unit teams and conflicts: Coordination between units is another CSF to the implementation of the BSC. Conflicts are more likely to arise when objectives are set by each individual unit rather than top management. However, empirical literature does not report much on the nature of such issues. It merely states that lack of coordination between departments poses a challenge during implementation (Fernandes et al., 2006; Kasurinen, 2002). Vice versa, the literature emphasizes the importance of collaboration and alignment across units (Chang et al., 2008). Overall, cross-unit cooperation can be increased if the units' managers are part of the BSC implementation team and thereby take responsibility for both their units and the overall goals of the organization (Chang et al., 2008; Kasperskaya, 2008).

\subsection{Cultural factors}

Studies rarely address culture as it is difficult to measure and difficult to relate to the BSC. Kasurinen (2002) conjectures that the incomplete BSC implementation in his case study is partly due to a strong engineering culture that sees the BSC as a measurement system for data, but rejects it as a management system that links operations to strategy. Modell (2009) explains how the number-driven BSC clashes with a pragmatist culture of simply getting things done in an informal way. In a similar vein, Butler et al. (1997) report how managers from the UK had problems accepting nonfinancial performance measures at eye-level with overall financial performance. This strong finance-driven culture truncated the BSC to three perspectives that are visual- 
ized as a triangle with the financial perspective on top. Perera et al. (2007) find two cultural barriers against the BSC in Australian councils: culture that is unwelcoming to change in general, and culture where employees can intransparently follow processes but are reluctant to see their end-result performance quantitatively measured. The study of Jazayeri and Scapens (2008) differentiates between a change in performance measurement and in culture. They document in detail how a 'value scorecard' is used to shift culture from strong managerial authority towards reliance on policies and empowerment through unit specialization.

\subsection{Political factors}

There is little in the literature on political factors and the BSC. Kasurinen (2002) documents a BSC implementation in an SBU that was initiated by the division management. It was not fully implemented as the responsible division manager resigned. The author then only hypothesizes that power struggles between the SBUs and the division would have broken lose if the division had pursued the implementation. Andon et al. (2007) report that political tension can prevent the seemingly simple exercise of picking the 'right' performance measures that are a reflection of strategy. The authors document a power struggle between the major shareholders of a telecommunications organization, i.e., the government and institutional investors. While the former sees as evident that the organization should invest into (sometime unprofitable) infrastructure and extensive service, the latter find it beyond dispute that the organization should optimize shareholder value and outperform competitors in several non-financial aspects. Interestingly, both shareholders (as well as several management groups) claimed to speak in the interest of the customers. Yet, they all reached different conclusions on which measures mattered. Among others, this dilemma prevented a sustainable BSC in the organization.

\subsection{Financial factors}

Implementing organizations appear simply to assume that the benefits of the BSC outweigh its costs. To our surprise, we cannot identify any article that reports on an organization that made a deliberate, calculated decision to implement the BSC. This could be very different in trade publications, non-peer-reviewed practitioner journals, or advertising brochures of consulting firms. Especially consultants could be eager to demonstrate that the benefits reaped from past BSC engagements exceeded their fees by far (Lueg, 2008, 2009). Thus, we encourage future research to stretch the boundaries of academic reviews and survey the practitioner literature in a separate effort. We expect that several results would surface that are neglected or contradictory to our review of peer-reviewed articles.

\subsection{Processual factors}

Another factor which is critical for a successful implementation is to follow up on the objectives, measures, and overall strategy. According to the suggestions by Kaplan and Norton (1996), organizations should try to validate the hypothesized cause-and-affect relationships by measuring the correlation between the measures. Lohman et al. (2004) show that the BSC must be updated to remain relevant to the organization. Contrary, the non-existence of a process owner will halt the implementation (Kasurinen, 2002). 
Further empirical literature actually indicates that successful organizations put much effort in reviewing the BSC once it has been deployed (Ahn, 2001; Kaplan \& Norton, 1993; Lohman et al., 2004; Papalexandris et al., 2004; Phadtare, 2010). To do so, managers track performance and take corrective actions wherever unfavorable deviations are found (Kaplan \& Norton, 1993; Phadtare, 2010). Meetings are held to assess the effectiveness of performance measures, the attainment of targets set, and the progress of strategic initiatives (Papalexandris et al., 2004). The correctness of the presumed chains of cause-and-effects are checked and the BSC is adapted if the causal relations cannot be confirmed. If the supposed causal relationships prove to be non-existent, it is regarded as a sign that the previously planned path towards the strategy implementation should be reconsidered (Ahn, 2001).

\subsection{Contextual factors}

Buchanan et al. (2005) see contextual factors as external pressure to adopt a practice, such as diffusion (Ansari et al., 2010) or isomorphism (DiMaggio \& Powell, 1983). Modell (2009) uncovers external pressure on a central government agency to implement the BSC. It is popularized in the agency by top managers who possess a business education. In addition to this, external consultants push an off-the-shelf version of the BSC as the latest management fashion upon the agency. Even though the BSC is not fully implemented in this case, some of its remains continue existing in the agency's control system. Perera et al. (2007) document that non-adopters among Australian councils exhibit the opposite characteristics, namely more old-fashioned top managers as well as a lack of competition and market pressure that would make a more complex management practice like the BSC necessary. Andon et al. (2007) present a similar case to Modell (2009) where the inconsistent, non-performance related motives become even clearer: a government demanded from its partly owned telecommunications organization that it adopt the BSC in order to achieve public legitimacy by following the trend on New Public Management. At the same time, this government blocked efficiency initiatives that resulted from the BSC implementation, such as cutting investments in unprofitable infrastructure. The study of Chang et al. (2008) in healthcare and Kasperskaya (2008) in public management report similar cases where the public discourse on efficiency forced public organizations into implementing the BSC.

\subsection{Temporal factors}

Contrary to many other management practices (Buchanan et al., 2005), temporal factors do not appear to play a major role in the BSC implementation literature and carry few surprises: Ahn (2001) emphasizes that gathering the needed data requires a great amount of time and resources. He thus suggests that it might be an advantage to introduce the measures into the organization step by step. Ong, Teh, Lau, \& Wong (2010) operationalize the perspectives of the BSC in a questionnaire. Their factor analysis suggests that each perspective is an independent construct, which suggest that the BSC is not a monolithic practice to be implemented all at once. But since the authors use a cross-sectional method, they can only make conjectures about possible sequential dependency of these constructs. Papalexandris et al. (2004) document how the BSC is implemented at a Greek software company in 7 steps. Their case is a 
Kaplan and Norton by-the-book implementation that appears to be streamlined. It starts with clarifying the strategy, drafting a strategy map of cause-and-effect relationships, defining objectives, measures, targets and initiatives, and implementing the BSC within 3 months.

Only Andon et al. (2007) delve deeper into the issue of sequence in BSC implementations. Following their case organization over 11 months, they refute the notion that an old management practice can be replaced all at once by the BSC. The authors build on the theory of relational drifting and show that there were several versions of the BSC that were altered in iterative processes, thereby negating the waterfall implementation model of Kaplan and Norton (1996). They also document that it is unrealistic to implement a BSC within a few months and that the achievement during this time frame was only sufficient to suggest a rough migration plan from the old to the new management practice.

\section{Discussion}

This study aims at improving the understanding of which factors play a role in a successful implementation of the BSC. In the first subsection, we discuss what we know about the CSFs of BSC implementations. In the second, we suggest what remains to be investigated. In the third, we distil the implications for BSC implementations in practice.

\subsection{The known critical success factors}

26 studies report on problems and success factors of BSC implementations. Despite the fact that our framework, based on Buchanan et al. (2005), already has 11 categories, we felt the need to detail them even further. This high number of CSFs suggests that a BSC implementation is more complex than suggested by Kaplan (Atkinson et al., 2011). Table 1 relates the reviewed sources to our framework.

Across the different settings of the studies, we find that some success factors are seen as especially relevant, i.e., substance, individual, and organizational factors. Most of the CSFs carry little surprise as they are the classic factors mentioned in every undergraduate textbook (Atkinson et al., 2011). As to the design, the BSC is often an add-on to other management practices which limits its authority as a basis for planning and control. Frequently, managers and employees struggle to include the appropriate type and number of indicators as their relationship to strategy or their mutual cause-and-effect relationships are not as obvious as suggested by the BSC's developers Kaplan and Norton. A further problem is that the BSC is often created by top managers and then cascaded into units, which can lead to a breach of controllability, i.e., middle managers are responsible for more than they can influence (Decoene \& Bruggeman, 2006). When organizations face these problems, they should consider alternative management practices, because most of these problems are inherent to the BSC and cannot be altered. As to individual factors, the BSC often faces resistance from employees that do not appreciate the increased transparency of their work, the constant monitoring, or at the other extreme, an amount of empowerment that some employees feel uncomfortable with. It is important to differentiate between this mentioned lack of willingness to adapt to the BSC and the lack of abilities to do so. Concerning the latter, managers need to communicate better to employees what the goals 
and the benefits of the BSC are. The literature suggests early involvement as a solution, but also mentions cases where employees abuse their involvement to game the BSC. As to resources, the literature concludes that the need for tangible resources is consistently underestimated, especially in terms of time, IT integration, and the budget. Success factors for the implementation are the use of rewards, cross-unit collaboration, and training on the BSC, although the literature holds no elaborate descriptions on how these should be designed and carried out.

\section{Table 1: Overview of reviewed studies and their characteristics}

\begin{tabular}{|c|c|c|c|c|c|c|c|c|c|c|c|c|}
\hline Source & & 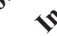 & & & & & & & से & & & $r$ \\
\hline Ahn (2001) & 0 & o & & & 0 & & & & & 0 & & 0 \\
\hline Aidemark (2002) & 0 & & & & & & & & & & & \\
\hline Akkermans and Van Oorschot (2004) & & & & & 0 & & & & & & & \\
\hline Andon, Baxter and Chua (2007) & o & o & & & o & & o & & & & o & 0 \\
\hline Butler, Letza and Neale (1997) & 0 & o & & & & & & & & & & \\
\hline Chan (2004) & & & & & $\mathrm{o}$ & & & & & & & \\
\hline Chang (2009) & & o & & & o & & & & & & & \\
\hline Chang, Tung, Huang and Yang (2008) & & & & & 0 & & & & & & $\mathrm{o}$ & \\
\hline Decoene and Bruggeman (2006) & $\mathrm{o}$ & & & & 0 & & & & & & & \\
\hline Elefalk (2001) & & o & & & & & & & & & & \\
\hline Evans (2005) & & o & & & o & & & & & & & \\
\hline Farneti (2009) & & & & & 0 & & & & & & & \\
\hline Fernandes, Raja and Whalley (2006) & 0 & $\mathrm{o}$ & & $\mathrm{o}$ & 0 & & & & & & & \\
\hline Garengo and Biazzo (2012) & o & & & & & & & & & & & \\
\hline Grando and Belvedere (2008) & 0 & o & & & & & & & & & & \\
\hline Jazayeri and Scapens (2008) & 0 & $\mathrm{o}$ & & & & $\mathrm{o}$ & & & & & & \\
\hline Kaplan and Norton (1993) & 0 & o & & & & & & & & 0 & & \\
\hline Kasperskaya (2008) & 0 & o & & 0 & o & & & & & & & \\
\hline Kasurinen (2002) & 0 & o & 0 & o & $\mathrm{o}$ & $\mathrm{o}$ & $\mathrm{o}$ & & & 0 & & \\
\hline Lohman, Fortuin and Wouters (2004) & & & & $\mathrm{O}$ & o & & & & & 0 & & \\
\hline McAdam and Walker (2003) & 0 & $\mathrm{o}$ & 0 & $\mathrm{O}$ & 0 & & & & & & & \\
\hline Modell, S. (2009) & 0 & o & & & o & $\mathrm{o}$ & & & & & o & \\
\hline Ong, Teh, Lau and Wong (2010) & & & & & & & & & & & & 0 \\
\hline Papalexandris, Ioannou and Prastacos (2004) & 0 & $\mathrm{o}$ & 0 & $\mathrm{O}$ & o & & & & & 0 & & $\mathrm{o}$ \\
\hline Perera, Schoch and Sabaratnam (2007) & & & & o & o & 0 & & & & & 0 & \\
\hline Phadtare (2010) & & & & $\mathrm{O}$ & & & & & & 0 & & \\
\hline SUM & 15 & 15 & 3 & 8 & 17 & 4 & 2 & - & & 6 & 4 & 4 \\
\hline
\end{tabular}

It is intriguing to note which factors are seen as crucial in the conceptual literature (Atkinson et al., 2011) but appear to be of less relevance in practice. One factor is the processual setup of a committee that revises the BSC on an ongoing basis. The literature does not say much about this, probably because it is crucial to sustain the practice, but not to implement it. Moreover, Kaplan and Norton (1996) urge organizations to implement the BSC within 16 weeks to preserve momentum. There is little documentation on the time frame even though it would be easily observable. Hence, it does not seem crucial. Yet given that the BSC should be constantly adjusted (Kaplan \& Norton, 2008a), it is hard to say when the implementation ends and the adjustment starts. Andon et al. (2007) show that their organization drafted several different BSCs during an 
implementation period of almost a year. They suggest that there is no end of an implementation but a 'drift' that diffuses the BSC very slowly over existing management practices.

\subsection{Open issues for future research}

When trying to determine which topics need more research, literature reviews always face the difficulty of understanding why some issues have not yet been addressed. One general possibility is that the researchers of the reviewed studies have already investigated the issue, gauged the non-findings irrelevant, and do not report them in their final articles. This is often a dead end for future research. The other possibility is that researchers have not asked questions on certain issues and hence did not identify the (well hidden) problems the organizations might actually have been facing. The latter possibility is highly interesting for future research and can be identified by two indicators: First, research on related topics has shown the relevance of the topic, and second, there is a pattern of research designs that favors some factors over the other.

Starting with the research pattern, we argue that there are three main categories of factors in the change literature: quantitative, such as an ex-ante cost-benefit analysis of the BSC implementation; somehow qualitative but still manifest factors, such as time and employee behavior; and finally latent factors, such as meta-communication of managers on the BSC to resolve conflicts. Table 1 suggests that the studies in our review have very well covered the qualitative aspects of the BSC implementations, such as the importance of organizational factors (i.e., resources) or individual factors (employee behavior). Yet, the other two fields are still underexplored. On the quantitative side, we still have little knowledge on how organizations gauge the costs and benefits before entering the costly BSC venture. And only one study attempts to juxtapose the budgeted and actual costs of a BSC implementation (Papalexandris et al., 2004). It would be necessary for empirical research to work with control groups, of which we have no reports so far: these organizations might have wished to implement the BSC but then refrained from doing so (cf. Perera et al., 2007) because they might have actually done a cost benefits analysis that turned out to be negative. On the latent side, many factors are hard to identify and measure. Table 1 indicates that few studies look at the meta-roles of power structures, isomorphism, or existing organizational culture. Furthermore, the researchers are often collaborating with managers and are thus overly exposed to their position. For instance, it is noteworthy that much attention is drawn to the resistance of employees (manifest problems of gaming measures and tweaking reports), but there is little evidence on the people skills the top/middle managers utilize to lead their employees in the right direction.

As to the relevance of some of these neglected factors, we refer to examples from management practices that can be seen as related to the BSC. For instance, studies show that public organizations are subject to contextual and political pressure to implement the BSC, such as public discourse and government initiatives, the influence of business school education, or consultants (Andon et al., 2007; Modell, 2009; Perera et al., 2007). It is likely that some implementations in the private sector are also driven by such non-economic motives. In fact, this is a well-known problem among the adopters of Value-based Management (Burkert \& Lueg, 2013; Fiss \& Zajac, 2004; 
Sanders \& Tuschke, 2007). Given that Strang and Macy (2001) propose that management practices keep diffusing long after they have been appraised ineffective, the implementation of an externally coerced BSC might prove an impossible task for an organization. Research that ignores context and politics might spuriously link the outcome of implementations to other factors such as employee resistance. As another example of a neglected factor, almost every study we reviewed employs the buzzword 'culture'. Yet, only few studies attempt to define what they mean by culture (e.g., Jazayeri \& Scapens, 2008) and how culture interacts with the BSC implementation. The importance of culture for future research is also highlighted by Kaplan and Norton, who frequently refer to this concept in their books.

\subsection{Implications for practice}

Our findings have several implications for practitioners implementing a BSC. We summarize them in Figure 2.

Figure 2 shows an assessment of which CSFs have received attention as being crucial in the conceptual literature (cf. section 2.2) and compares them to the most relevant factors according to empirical studies. It is intriguing to notice that Kaplan emphasizes timely management and processual factors, but these CSFs have not proven to be crucial in the empirical studies we reviewed. Thus, these CSFs might be seen as OVERRATED. We hence advise managers to deprioritize these CSFs to focus attention toward the more relevant categories. Of course, managers need to manage the INTUITIVE CSFS (cf. Figure 2). But CSFs BLIND SPOTS are the most interesting: the conceptual guidelines on these CSFs are scarce, but their relevance in practice is high. Hence, managers will not even expect to get under pressure in these fields. They should devote much attention to understand these CSFs better and anticipate problems. An important blind spot is the financial litmus test for any project: managers should make a well-documented argument why the company will be better off with the BSC than any other alternative (CSF 4.8). Yet, we have not found in any empirical evidence that this has been done. All other blind spot CSFs are quite abstract. Hence, they easily slip managerial attention, and it takes effort to manage them: managers must keep a critical attitude toward the BSC, think the implementation through at least to the level of middle management, and be open to admit their own mistakes (CSF 4.3). They must account for the fact that the BSC can conflict with organizational culture in case employees are not ready to be measured, or not ready to accept non-financial measurements (CSF 4.6). Last, managers must admit that not only economic rationale drives the decision for the optimal management systems: power, politics, and pressure to adopt the latest 'fashion' will impinge the way the BSC will finally be implemented (CSFs 4.7 and 4.10). We provide an example where an organization was forced to adopt the BSC for window dressing, but any consequent improvements in efficiency were then blocked as politically unwanted (Andon et al., 2007).

In conclusion, this paper provides insight into the implementation process of the BSC to organizations that are contemplating an implementation. Our review helps managers to focus on the 'blind spots' of BSC implementations instead of focusing 
Figure 2: The blind spots in Critical Success Factors for BSC implementations: attention vs. relevance

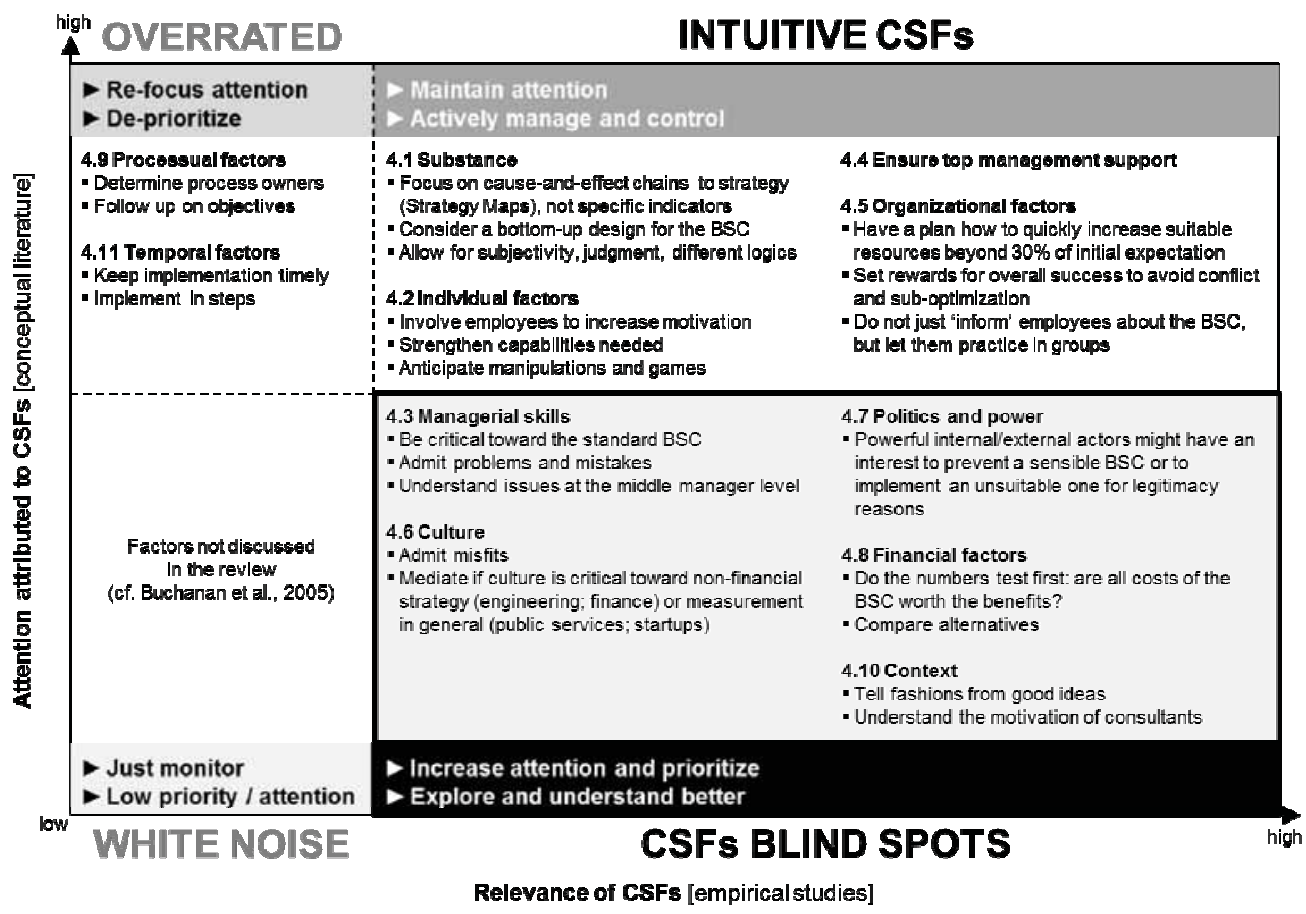

Legend:

All CSFs in the four matrix categories are numbered according to their section number in the findings section. The y-axis (lowhigh) categorizes them according to the attention the conceptual literature has attributed to these CSFs. The x-axis (low-high) categorizes CSFs based on the relevance these CSFs had in actual BSC implementations. We named each quadrant, describe the CSFs related to it (numbered by their section) and suggest managerial action for each quadrant:

OVERRATED: these CSFs are attracting attention in the conceptual literature, but are not seen equally relevant in actual implementations. Managers should refocus their attention toward the more important blind spots.

INTUITIVE CSFs: these CSFs should receive attention by managers because they are seen as equally important in the conceptual and empirical literature.

CSFS BLIND SPOTS: these CSFs often slip the attention of managers. They only become apparent when the BSC implementation is challenged. Managers need to actively put these on the top of their agenda and devote the due attention to these mostly quite abstract CSFs.

WHITE NOISE: these are factors that do not relate directly to BSC implementations and were hence not discussed.

on the 'overrated' CSFs that needlessly absorb managers' attention. Such a better understanding of CSFs is a necessary capability that may lead to more successful implementations in future. Last, our review suggests potential future research topics to further facilitate this understanding of BSC implementations.

\section{References}

Ahn, H. (2001). Applying the Balanced Scorecard concept: An experience report. Long Range Planning, 34(4), 441-461.

Aidemark, L. G. (2002). The meaning of Balanced Scorecards in the health care organisation. Financial Accountability \& Management, 17(1), 23-40. 
Akkermans, H. A., \& Van Oorschot, K. E. (2004). Relevance assumed: a case study of Balanced Scorecard development using system dynamics. Journal of the Operational Research Society, 56(8), 931-941.

Albertsen, O. A., \& Lueg, R. (2014). The Balanced Scorecard's missing link to compensation: a literature review and an agenda for future research. Journal of Accounting and Organizational Change, 10(4), 431-465.

Andon, P., Baxter, J., \& Chua, W. F. (2007). Accounting change as relational drifting: a field study of experiments with performance measurement. Management Accounting Research, 18(2), 273-308.

Anonymous (2001). Balanced Scorecard is fast becoming a must have process for corporate change. Management Services, 45(8), 5-6.

Ansari, S. M., Fiss, P. C., \& Zajac, E. J. (2010). Made to fit: how practices vary as they diffuse. Academy of management review, 35(1), 67-92. doi: 10.5465/amr.2010.45577876

Atkinson, A. A., Kaplan, R. S., Matsumura, E. M., \& Young, S. M. (2011). Management Accounting, International Edition (6th ed.). New Jersey, NJ: Pearson.

Barki, H., \& Pinsonneault, A. (2005). A model of organizational integration, implementation effort, and performance. Organization Science, 16(2), 165-179.

Buchanan, D., Fitzgerald, L., Ketley, D., Gollop, R., Jones, J. L., Lamont, S. S., \& Whitby, E. (2005). No going back: a review of the literature on sustaining organizational change. International Journal of Management Reviews, 7(3), 189-205.

Burkert, M., \& Lueg, R. (2013). Differences in the sophistication of Value-based Management - The role of top executives. Management Accounting Research, 24(1), 3-22.

Butler, A., Letza, S. R., \& Neale, B. (1997). Linking the Balanced Scorecard to strategy. Long Range Planning, 30(2), 242-153.

Chan, Y.-C. L. (2004). Performance measurement and adoption of Balanced Scorecards: A survey of municipal governments in the USA and Canada. International Journal of Public Sector Management, 17(3), 204-221.

Chang, H. H. (2009). An empirical study of evaluating supply chain management integration using the Balanced Scorecard in Taiwan. The Service Industries Journal, 29(2), 185-202.

Chang, W.-C., Tung, Y.-C., Huang, C.-H., \& Yang, M.-C. (2008). Performance improvement after implementing the Balanced Scorecard: a large hospital's experience in Taiwan. Total Quality Management, 19(11), 1143-1154.

Chenhall, R. H. (2003). Management control systems design within its organizational context: findings from contingency-based research and directions for the future. Accounting, Organizations and Society, 28(2-3), 127-168.

Decoene, V., \& Bruggeman, W. (2006). Strategic alignment and middle-level managers' motivation in a Balanced Scorecard setting. International journal of operations \& production management, 26(4), 429-448.

Denyer, D., \& Tranfield, D. (2009). Producing a systematic review. In D. Buchanan \& A. Bryman (Eds.), The Sage Handbook of Organizational Research Methods (pp. 671-689). London: Sage.

DiMaggio, P. J., \& Powell, W. W. (1983). The iron cage revisited: Institutional isomorphism and collective rationality in organizational fields. American Sociological Review, 48(2), 147-160.

Elefalk, K. (2001). The Balanced Scorecard of the Swedish police service: 7000 officers in total quality management project. Total Quality Management, 12(7-8), 958-966.

Evans, N. (2005). Assessing the Balanced Scorecard as a management tool for hotels. International Journal of Contemporary Hospitality Management, 17(5), 376-390.

Farneti, D. F. (2009). Balanced Scorecard implementation in an Italian local government organization. Public Money \& Management, 29(5), 313-320.

Fernandes, K. J., Raja, V., \& Whalley, A. (2006). Lessons from implementing the Balanced Scorecard in a small and medium size manufacturing organization. Technovation, 26(5), 623-634.

Fiss, P. C., \& Zajac, E. J. (2004). The diffusion of ideas over contested terrain: the (non)adoption of a shareholder value orientation among German firms. Administrative science quarterly, 49(4), 501-534.

Garengo, P., \& Biazzo, S. (2012). Unveiling strategy in SMEs through Balanced Scorecard implementation: a circular methodology. Total Quality Management \& Business Excellence, 23(1), 79-102.

Grando, A., \& Belvedere, V. (2008). Exploiting the Balanced Scorecard in the operations department: The Ducati Motor Holding case. Production Planning and Control, 19(5), 495-507. 
Harvey, C., Kelly, A., Morris, H., \& Rowlinson, M. (2010). Academic journal quality guide. London: The Association of Business Schools.

Hoque, Z. (2014). 20 years of studies on the Balanced Scorecard: Trends, accomplishments, gaps and opportunities for future research. The British Accounting Review, 45(1), 33-59.

Ittner, C. D., \& Larcker, D. F. (2001). Assessing empirical research in managerial accounting: A Valuebased management perspective. Journal of Accounting \& Economics, 32(1-3), 349-410.

Jakobsen, M., \& Lueg, R. (2012). The Balanced Scorecard: The illusion of maximization without constraints. Proceedings of Pragmatic Constructivism, 2(1), 10-15.

Jakobsen, M., \& Lueg, R. (2014). Balanced Scorecard and controllability at the level of middle managers The case of unintended breaches. Journal of Accounting and Organizational Change, 10(4), 516-539.

Jazayeri, M., \& Scapens, R. W. (2008). The business values scorecard within BAE systems: The evolution of a performance measurement system. The British Accounting Review, 40(1), 48-70.

Kaplan, R. S., \& Norton, D. P. (1992). The Balanced Scorecard - Measures that drive performance. Harvard business review, 70(1), 71-79.

Kaplan, R. S., \& Norton, D. P. (1993). Implementing the Balanced Scorecard at FMC corporation: An interview with Larry D. Brady. Harvard business review, 71(5), 143-147.

Kaplan, R. S., \& Norton, D. P. (1996). The Balanced Scorecard: Translating strategy into action. Boston, MA: Harvard Business School Press.

Kaplan, R. S., \& Norton, D. P. (2001a). The strategy-focussed organization: How balanced scorecard companies thrive in the new business environment. Boston, MA: Harvard Business School Press.

Kaplan, R. S., \& Norton, D. P. (2001b). Transforming the Balanced Scorecard from performance measurement to strategic management: Part I. Accounting Horizons, 15(1), 87-104.

Kaplan, R. S., \& Norton, D. P. (2001c). Transforming the Balanced Scorecard from performance measurement to strategic management: Part II. Accounting Horizons, 15(2), 147-160.

Kaplan, R. S., \& Norton, D. P. (2004a). How strategy maps frame an organization's objectives. Financial Executive, 20(2), 40-45.

Kaplan, R. S., \& Norton, D. P. (2004b). Strategy maps: Converting intangible assets into tangible outcomes. Boston, MA: Harvard Business Press.

Kaplan, R. S., \& Norton, D. P. (2006). Alignment: Using the Balanced Scorecard to create corporate synergies. Boston, MA: Harvard Business School Press.

Kaplan, R. S., \& Norton, D. P. (2008a). The execution premium: Linking strategy to operations for competitive advantage. Boston, MA: Harvard Business Press.

Kaplan, R. S., \& Norton, D. P. (2008b). Mastering the management system. Harvard business review, 86(1), 62-77.

Kasperskaya, Y. (2008). Implementing the Balanced Scorecard: A comparative study of two Spanish city councils - An institutional perspective. Financial Accountability \& Management, 24(4), 363-384.

Kasurinen, T. (2002). Exploring management accounting change: The case of Balanced Scorecard implementation. Management Accounting Research, 13(3), 323-343.

Khan, K. S., ter Riet, G., Glanville, J., Sowden, A. J., \& Kleijnen, J. (Eds.) (2001). Undertaking systematic reviews of research on effectiveness (2nd ed.). York: Centre for Reviews and Dissemination, University of York.

Lawson, R., Desroches, D., \& Hatch, T. (2008). Scorecard best practices: Design, implementation, and evaluation: John Wiley \& Sons.

Lohman, C., Fortuin, L., \& Wouters, M. (2004). Designing a performance measurement system: A case study. European Journal of Operational Research, 156(2), 267-286.

Lueg, R. (2008). Value-based management: Empirical evidence on its determinants and performance effects. Vallendar: WHU Otto Beisheim School of Management.

Lueg, R. (2009). Führt der Einsatz externer Berater zur Überimplementierung innovativer Steuerungsinstrumente? Zeitscbrift der Unternehmensberatung, 4(6), 249-253.

Lueg, R. (2015). Strategy maps: The essential link between the Balanced Scorecard and action. Journal of Business Strategy, 36(2), 34-40.

Lueg, R., \& Carvalho e Silva, A. L. (2013). When one size does not fit all: a literature review on the modifications of the Balanced Scorecard. Problems and Perspectives in Management, 11(3), 86-94. 
Lueg, R., \& Julner, P. (2014). How are strategy maps linked to strategic and organizational change? A review of the empirical literature on the Balanced Scorecard. Corporate Ownership \& Control, 11(4), 439-446.

Lueg, R., \& Nørreklit, H. (2012). Performance measurement systems - Beyond generic strategic actions. In F. Mitchell, H. Nørreklit, \& M. Jakobsen (Eds.), The Routledge companion to cost management (pp. 342359). New York, NY: Routledge.

Lueg, R., \& Schäffer, U. (2010). Assessing empirical research on value-based management: Guidelines for improved hypothesis testing. Journal für Betriebswirtschaft, 60(1), 1-47.

Marr, B. (2001). Scored for life. Financial Management, 30(4), 30.

McAdam, R., \& Walker, T. (2003). An inquiry into Balanced Scorecards within best value implementation in UK local government. Public Administration, 81(4), 873-892.

Modell, S. (2009). Bundling management control innovations: a field study of organisational experimenting with total quality management and the Balanced Scorecard. Accounting, Auditing \& Accountability Journal, 22(1), 59-90.

Niven, P. R. (2011). Balanced Scorecard: Step-by-step for government and nonprofit agencies. Hoboken, NJ: Wiley.

Northcott, D., \& Taulapapa, T. M. (2012). Using the Balanced Scorecard to manage performance in public sector organizations: Issues and challenges. International Journal of Public Sector Management, 25(3), 166-191.

Nørreklit, H. (2000). The balance on the Balanced Scorecard: A critical analysis of some of its assumptions. Management Accounting Research, 11(1), 65-88. doi: 10.1006/mare.1999.0121

Nørreklit, H. (2003). The Balanced Scorecard: What is the score? A rhetorical analysis of the Balanced Scorecard. Accounting, Organizations and Society, 28(6), 591-619.

Nørreklit, H., Jakobsen, M., \& Mitchell, F. (2008). Pitfalls in using the balanced scorecard. Journal of Corporate Accounting \& Finance, 19(6), 65-68.

Nørreklit, H., Nørreklit, L., Mitchell, F., \& Biørnenak, T. (2012). The rise of the Balanced Scorecard Relevance regained? Journal of Accounting and Organizational Change, 8(4), 490-510.

Ong, T. S., Teh, B. H., Lau, C. K., \& Wong, S. L. S. (2010). Adoption and implementation of Balanced Scorecard in Malaysia. Management Accounting Journal, 5(1), 21-40.

Papalexandris, A., Ioannou, G., \& Prastacos, G. P. (2004). Implementing the Balanced Scorecard in Greece: A software firm's experience. Long Range Planning, 37(4), 351-366.

Perera, S., Schoch, H., \& Sabaratnam, S. (2007). Adoption of the Balanced Scorecard in local government organizations: an exploratory study. Asia-Pacific Management Accounting Journal, 2(1), 53-70.

Phadtare, M. T. (2010). Developing Balanced Scorecard: Case of three construction firms of small size. Journal of Asia-Pacific Business, 11(2), 135-157.

Rigby, D. K. (2013). Management tools 2013 - An executive's guide. Boston, MA: Bain \& Comapny.

Rousseau, D. M., Manning, J., \& Denyer, D. (2008). Evidence in management and organizational science: assembling the field's full weight of scientific knowledge through syntheses. Academy of Management Annals, 2(1), 475-515. doi: 10.1080/19416520802211651

Sanders, W. G., \& Tuschke, A. (2007). The adoption of institutionally contested organizational practices: The emergence of stock option pay in Germany. Academy of Management Journal, 50(1), 33-57.

Simons, R. (2005). Levers of organization design: How managers use accountability systems for greater performance and commitment. Boston, MA: Harvard Business Press.

Speckbacher, G., Bischof, J., \& Pfeiffer, T. (2003). A descriptive analysis on the implementation of Balanced Scorecards in German-speaking countries. Management Accounting Research, 14(4), 361-388.

Strang, D., \& Macy, M. W. (2001). In search of excellence: Fads, success stories, and adaptive emulation. American Journal of Sociology, 107(1), 147-182.

Tranfield, D., Denyer, D., \& Smart, P. (2003). Towards a methodology for developing evidence: Informed management knowledge by means of systematic review. British journal of management, 14(3), 207-222.

Van de Ven, A. H., \& Poole, M. S. (2005). Alternative approaches for studying organizational change. Organization Studies, 26(9), 1377-1404.

Williams, S. (2001). Drive your business forward with the Balanced Scorecard. Management Services, 45(6), 28-30.

Zimmerman, J. L. (2001). Conjectures regarding empirical managerial accounting research. Journal of Accounting \& Economics, 32(1-3), 411-427. 